\title{
Flow Cytometric Estimation of the Effect of Ginkgo Biloba Extract on the Content of Hydrogen Peroxide in Dissociated Mammalian Brain Neurons
}

\author{
Yasuo Oyama ${ }^{1}$, Toshiko Ueha ${ }^{1}$, Akemi Hayashi $^{1}$, Lumi Chikahisa $^{1, \#}$ and Katsuhiko Noda ${ }^{2}$ \\ 'Laboratories for Pharmacology and ${ }^{2}$ Fond Science, Faculy of Integrated Arts and Sciences, \\ The University of Tokushima, Tokushima 770, Japan
}

Received August 19,1992 Accepted October 6, 1992

\begin{abstract}
The effect of Ginkgo biloba extract (GBE) on the content of hydrogen peroxide was estimated in cerebellar neurons dissociated from rats, by means of a flow-cytometer and 2',7'-dichlorofluorescin (DCF) diacetate, a fluorescent dye for intracellular hydrogen peroxide. The GBE started to reduce the DCF fluorescence of the neuron at $0.1 \mu \mathrm{g} / \mathrm{ml}$ to $0.3 \mu \mathrm{g} / \mathrm{ml}$. Further increases in the GBE concentration (up to $3 \mu \mathrm{g} / \mathrm{ml}$ ) produced a dose-dependent decrease in the DCF fluorescence, suggesting that GBE reduces the content of hydrogen peroxide or suppresses the reactive oxygen species (ROS) formation of cerebellar neurons. The present technique may be useful for preliminary evaluations of agents affecting the ROS formation in mammalian brain neurons.
\end{abstract}

Keywords: Ginkgo biloba extract, Brain neuron, Hydrogen peroxide

It is widely accepted that there are reactive oxygen species (ROS) that may be involved in ischemic and/or postischemic brain damagc $(1-4)$. Thus, the membranc phospholipids of the brain neurons undergo peroxidation induced by the ROS because of their high content of polyunsaturated fatty acids. Therefore, agents that prevent ROS formation are expected to exert some protective actions on brain neurons subjected to ischemia. ROS such as superoxide anion, hydrogen peroxide and hydroxyl radicals are produced in biological systems even under normal conditions (5). However, there is no conventional technique for evaluating the effect of agents on intracellular ROS formation in dissociated mammalian brain neurons.

2',7'-Dichlorofluorescin diacetate (DCFH-DA) diffuses across the cell membrane and is then trapped by cellular deacetylation. Intracellular hydrogen peroxide oxidizes this compound to $2^{\prime}, 7^{\prime}$-dichlorofluorescin (DCF), which is highly fluorescent (6). Since this property of DCFH-DA has been utilized to estimate the ROS formation in neutrophils and polymorphonuclear leukocytes by measuring intracellular hydrogen perox-

\footnotetext{
\#Present address: Taiho Pharmaceutical Co., Ltd., Kawauchi, Tokushima 771-01, Japan
}

ide (7-9), we have designed an approach to estimate the effect of the agent on the intracellular hydrogen peroxide content on dissociated mammalian brain neurons, using DCFH-DA and a flow cytometer. The present studies were designed to determine if the extract of Ginkgo biloba (GBE) is able to affect the hydrogen peroxide content of mammalian brain neurons, because the GBE, which contains flavone glycosides, biobalide and ginkgolides (10), has been reported to protect the brain against hypoxic damage, prolong the survival of rats (11) and to inhibit the ROS formation of leukocytes (12).

Experiments were performed on cerebcllar ncurons dissociated from 1- to 2-week-old Wistar rats. The techniques for dissociation of rat cerebellar neurons and measurement of fluorescence were previously reported (13). Briefly, the slices $(0.5 \mathrm{~mm}$ in width) of rat cerebellum were treated with dispase $\left(10^{3} \mathrm{PU} / \mathrm{ml}\right.$; Godo Shusei Co., Japan) for $60 \mathrm{~min}$ in Tyrode's solution at the temperature of $35-36 \mathrm{C}$. Thereafter, the cerebellar neruons were dispersed by gentle pipetting in Tyrode's solution. Tyrode's solution containing dispersed neurons (the cell suspension) was filtered through a mesh (diameter of $53 \mu \mathrm{m}$ ) to remove larger neurons and the residua. Since the neurons in the filtered cell 
suspension were characterized by their small size (diameter of about $10 \mu \mathrm{m}$ ) and spherical shape under microscopic observation, the cells were likely cerebellar granule neurons. Fluorescence measurement from dye-stained neurons performed with a flow-cytometer equipped with an argon laser (Cyto-ACE 150, Japan Spectroscopic Co., Japan). Chemicals except for the dyes were purchased from Katayama Chemicals Co., Japan.

As shown in Fig. 1a, the cytogram (cell size versus cell density or forward-angle light scatter versus side light scatter, right panel of Fig. 1) of cell suspension revealed two populations. Without the fluorescent dyes, the fluorescence from both populations was minimum under the programmed condition of bandpass filter described bclow. To examine the viability of dissociated cerebellar neurons in the spot, $5 \mu \mathrm{M}$ acridine orange (ACO; Chroma-Gesellshaft, Germany) and $10 \mu \mathrm{M}$ ethidium bromide (ETB; Molecular Probe, U.S.A.) were added to the cell suspension (14). The excitation wavelength used for these dyes was $488 \mathrm{~nm}$, and the emission was detected at the wavelength of $600 \pm 20$ $\mathrm{nm}$ for ETB and $530 \pm 20 \mathrm{~nm}$ for ACO, respectively, by the bandpass filter. The fluorescence cytogram $(600$ $\pm 20 \mathrm{~nm}$ versus $530 \pm 20 \mathrm{~nm}$, left panel of Fig. 1) obtained from the cell suspension indicated two populations (Fig. 1b). Thus, one population was intensively stained with ACO, but not with ETB (Fig. 1c), suggesting that the population consists of live neurons. Another was stained vice versa (Fig. 1d), corresponding to dead neurons. Therefore, the experiments for DCF fluorescence were carried out on the population consisting of live neurons.

To estimate the content of hydrogen peroxide in cerebellar neurons, DCFH-DA was added to the cell suspension to achieve a final concentration of $100 \mu \mathrm{M}$ or $150 \mu \mathrm{M}$. The neurons were incubated with DCFH$\mathrm{DA}$ at $35-36^{\circ} \mathrm{C}$ for $60 \mathrm{~min}$ before the fluorescence measurement, since the steady level of the DCF fluorescence was obtained at 45 to 60 min after adding the dye. The excitation wavelength used for intracellular DCF was $488 \mathrm{~nm}$, and the emission was detected at the wavelength of $530 \pm 20 \mathrm{~nm}$. Fluorescence intensity was resolved into 255 channels, and the histogram for the DCF fluorescence was obtained from a programmed number of neurons by using a personal computer (PC-9801RX, NEC, Japan) and the software developed by Japan Spectroscopic Co. The DCF fluorescence histogram obtained from the neurons in the cell suspension with DCFH-DA was distinct from that without the dye (Fig. 2a). The mean channel number increased from the control (no fluorescence dye) value of 28.1 \pm 9.7 (mean \pm S.D. of 3500 cells) to $154.6 \pm 25.6$, indicating an increase in the DCF fluorescence. The

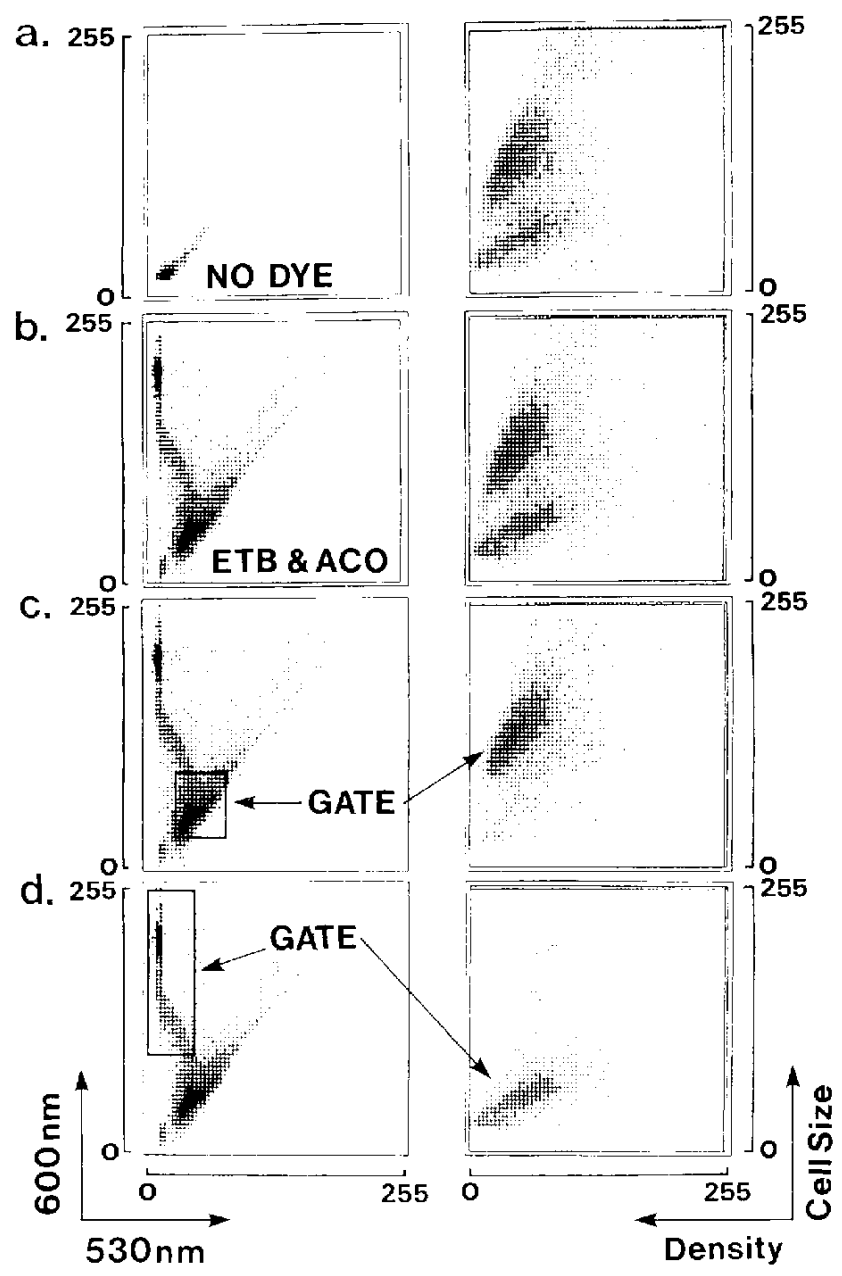

Fig. 1. Cytograms obtained from the suspension containing rat cerebellar neurons by a flow cytometer. The left cytogram indicates the fluorescence $(600 \pm 20 \mathrm{~nm}$ versus $530 \pm 20 \mathrm{~nm})$. Abscissa: $600 \pm 20 \mathrm{~nm}$, ordinate: $530 \pm 20 \mathrm{~nm}$. The right pancl (cytogram) shows the cell size versus cell density (forward-angle light scatter versus side light scatter) of the dissociated neurons. Abscissa: cell size, ordinate: cell density. Fluorescence intensity was resolved to 255 channels. (a) Cytograms obtained from the neurons without the dycs. The fluorescence detected from the neurons was minimum as shown in the left panel. (b) Cytograms obtained from the neurons stained with $5 \mu \mathrm{M}$ ethidium bromide (ETB) and $10 \mu \mathrm{M}$ acridine orange (ACO). The fluorescence intensitics detected at $600 \pm 20 \mathrm{~nm}$ (abscissa: detected for ETB) and $530 \pm 20 \mathrm{~nm}$ (ordinate: detected for $\mathrm{ACO}$ ) were increased. (c) Gating of the neurons stained with ACO rather than ETB indicates the live cell population in the cytogram of cell size versus cell density as shown in the right pancl. (d) Gating of the neurons stained with ETB rather than ACO indicated the dead cell population indicated in the right panel.

fluorescence intensities obtained from cerebellar neurons with and without the dye was practically constant during the next $60 \mathrm{~min}$.

The extract from green leaves of Ginkgo biloba, obtained from Japan Greenwave, Ltd. (Tokyo, Japan), 

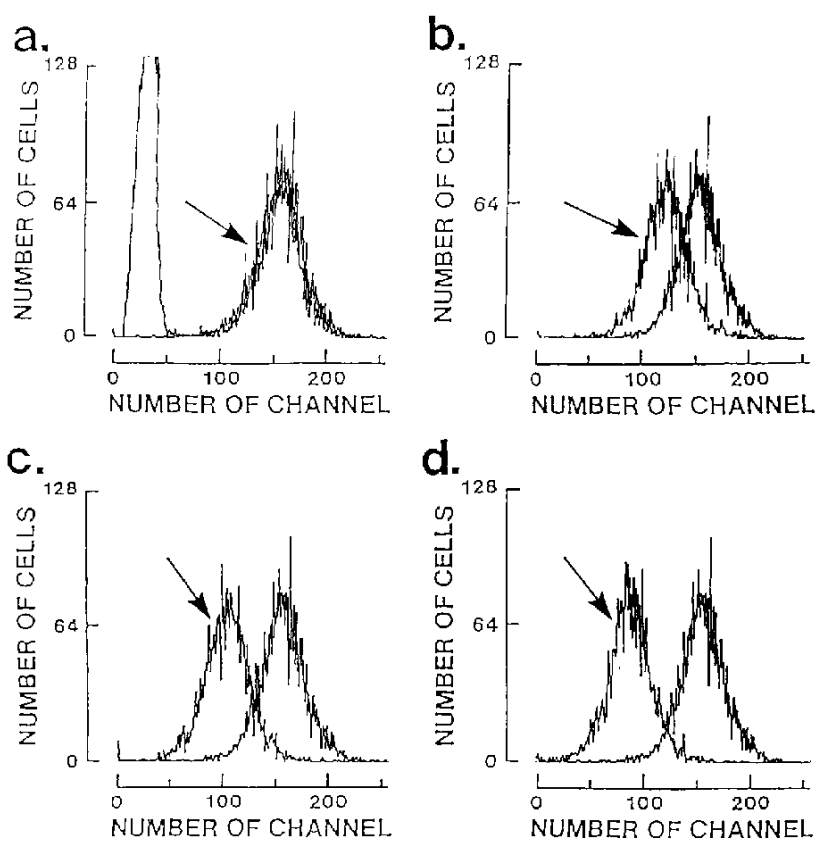

e.

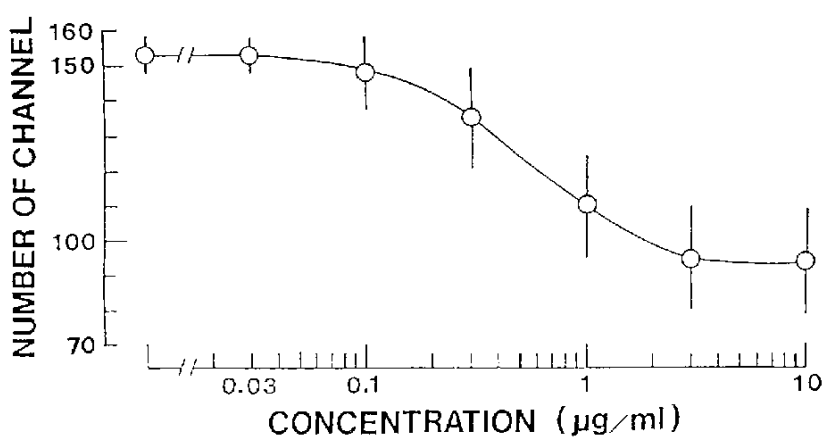

Fig. 2. Effect of the extract of Ginkgo biloba (GBE) on the dichlorofluorescin (DCF) fluorescence profile obtained from 3500 cerebellar neurons. Histograms represent the fluorescence distribution in the neurons. Fluorescence intensity was resolved into 255 channels as shown in the abscissa. Values at the ordinate correspond to the number of ncurons at each channel. (a) The fluorescence histograms obtained from the neurons without $2^{\prime}, 7^{\prime}$ dichlorofluorescin diacetate (left histogram), with the dye in the absence of GBE (control: right one without arrow), and with the dye in the presence of $0.1 \mu \mathrm{g} / \mathrm{ml} \mathrm{GBE}$ (right one with arrow). (b-d) The histograms of DCF fluorescence were obtained in the control and in the presence of GBE (indicated with the arrow) at the following concentrations: (b) $0.3 \mu \mathrm{g} / \mathrm{ml}$, (c) $1.0 \mu \mathrm{g} / \mathrm{ml}$, and (d) $3.0 \mu \mathrm{g} / \mathrm{ml}$. The figure shows a representative one from six experiments. (e) Dose-response curve for the GBE in decreasing the mean channel value of DCF fluorescence in dissociated cerebellar neurons. Each symbol indicates the average of the mean channel value and standard deviation of 4-6 experiments. Lift symbol shows the control value before drug-application. The respective experiment was performed on $3500-5000$ neurons.

was dissolved at the concentration of $10 \mathrm{mg}$ per $\mathrm{ml}$ of ethanol. The dissociated neurons were incubated with GBE at appropriate concentrations for $60 \mathrm{~min}$. The fi- nal concentration of ethanol as a solvent was less than $0.1 \%$, and this solvent concentration did not affect the DCF fluorescence measurement. Thereafter, DCFHDA was added to the cell suspension to estimate the effect of GBE on the content of hydrogen peroxide. Therefore, the effect of GBE on cerebellar neurons was examined at $120 \mathrm{~min}$ after adding the GBE to the cell suspension. Under this procedure, the effect of GBE seemed to reach the stcady-state because there was no significant change in DCF fluorescence intensity during the next $60 \mathrm{~min}$. The GBE started to decrease the fluorescence intensity of DFC at the concentration of 0.1 to $0.3 \mu \mathrm{g} / \mathrm{ml}$ (Fig. 2, a and b). The DCF fluorescence was reduced to $150.7 \pm 33.7$ (mean channel number \pm S.D. of 3500 cells) from the control value of $154.6 \pm 25.6$ in the presence of $0.1 \mu \mathrm{g} / \mathrm{ml}$ of GBE. Increasing the concentration (up to $3.0 \mu \mathrm{g} / \mathrm{ml}$ ) produced a further decrease in the DCF fluorescence (Fig. 2, c and $\mathrm{d}$ ). Thus, the channel number dose-dependently decreased to $123.6 \pm 25.3,102.9 \pm 25.8$, and $87.2 \pm$ 24.0 at the GBE concentration of $0.3 \mu \mathrm{g} / \mathrm{ml}, 1.0$ $\mu \mathrm{g} / \mathrm{ml}$, and $3.0 \mu \mathrm{g} / \mathrm{ml}$, respectively. However, at GBE concentrations greater than $3.0 \mu \mathrm{g} / \mathrm{ml}$, a further significant decrease in the DCF fluorescence was not observed. Thus, the intensity of DCF fluorescence in the presence of $3 \mu \mathrm{g} / \mathrm{ml}$ of GBE was similar to those obtained in the presence of $10 \mu \mathrm{g} / \mathrm{ml}$ of GBE (not shown). The dose-response curve for GBE in decreasing the mean channel number of the DCF fluorescence histogram is shown in Fig. 2e.

There is no conventional technique for evaluating the effect of agents on the intracellular ROS formation of dissociated brain neurons, yet this is important for developing means to protect brain neurons against the damages caused by ischemia (1-4). DFC fluorescence has been used to estimate the ROS formation or the oxidative metabolism of leukocytes $(7,8)$, since this compound is oxidized by intracellular hydrogen peroxide, an intermediate in the oxidative metabolism. Thus, the superoxide anion is converted by superoxide dismutase to hydrogen peroxide (5). Furthermore, $\mathrm{Fe}^{2+}$ reacts with hydrogen peroxide to produce hydroxyl radicals (3). Therefore, DCFH-DA may also be suitable for estimating the level of cellular ROS formation by measuring the content of hydrogen peroxide. In this study, we have utilized the fluorescence property of DCFH-DA to estimate the action of the agents on the ROS (or oxidative metabolism) in mammalian brain neurons. The GBE dose-dependently reduced the DFC fluorescence of cerebellar neurons in the present study (Fig. 2). One may argue that there may be a possibility that the GBE interacts directly with DCFH-DA and/or DCF, resulting in the decrease in DCF fluorescence. 
However, this is unlikely because the potency of GBE in decreasing the DCF fluorescence was independent of the DCFH-DA concentration in a preliminary study using mouse thymocytes, and because the saturation of GBE action on the DCF fluorescence was observed in this study (Fig. 2). Furthermore, flunarizine which has been reported to exert free radical scavenging or antioxidant activity (15), also reduced the DCF fluorescence of dissociated mammalian brain neurons more profoundly than pentobarbital, diltiazem and verapamil (Y. Oyama et al., unpublished results). Therefore, the present results suggest the possibility that GBE, at concentrations ranging from $0.1 \mu \mathrm{g} / \mathrm{ml}$ to $3 \mu \mathrm{g} / \mathrm{ml}$, reduces the intracellular ROS formation of mammalian brain neurons in a dose-dependent manner. Such an action of GBE may contribute to its protection of brain tissue against ischemic or hypoxic damage (11). Since the GBE used in this study was a crude preparation, the threshold concentration of active substances in the crude extract is thought to be lower than $0.1 \mu \mathrm{g} / \mathrm{ml}$. It is yet unclear which of the compounds are responsible for the pharmacological activities of GBE; further experiments will be necessary to identify these components.

\section{Acknowledgments}

This study was partly supported by the Research Grant awarded to Y. Oyama from the Ciba Geigy Foundation (Japan) for Promoting Sciences and by a Grant-in-Aid from the Minister of Education. Science and Culture, Japan (No. 03807009).

\section{REFERENCES}

1 Flamm, E.S., Demopoulos, H.B., Seligman, M.L., Poser, R.G. and Ransohoff, J.: Free radicals in cerebral ischemia. Stroke 9, 445-447 (1978)

2 Siesjo, B.K.: Cell damage in the brain: A speculative synthesis. J. Cereb. Blood Flow Metab. 1, 155-185 (1981)

3 McCord, J.M.: Oxygen-derived free radicals in the post ischemic tissue injury. N. Engl. J. Med. 312, 159-163 (1985)

4 Kogure, K., Arai, H., Abe, K. and Nakano, M.: Free radical damage of the brain following ischemia. Prog. Brain Res. 63, $237-259$ (1985)

5 Fridovich, I.: The biology of oxygen radicals. The superoxide radical is an agent of oxygen toxicity; superoxide dismutase provides an important defense. Science 201, 875-880 (1978)

6 Keston, A.S. and Brandt, R.: The fluorometric analysis of ultramicro quantities of hydrogen peroxide. Anal. Biochem. $11,1-5(1965)$

7 Bass, D.A., Olbrantz, P., Szejda, P., Seeds, M.C. and McCall, C.E.: Subpopulations of neutrophils with increased oxidative product formation in blood of patients with infection. J. Immunol. 136, 860-866 (1986)

8 Bass, D.A., Parce, J.W., Dechatelet, L.R., Szeida, P., Sceds, M.C. and Thomas, M.: Flow cytometric studies of oxidative product formation by neutrophils: A graded response to membranc stimulation. J. Immunol. 130, 1910-1917 (1983)

9 Seeds, M.C., Parce, J.W., Szejda, P. and Bass, D.A.: Independent stimulation of membrane potential changes and the oxidative metabolic burst in polymorphonuclear leukocytes. Blood 65, 233-240) (1985)

10 Weinges, K., Bachr, W. and Kloss, P.: Übersicht über die Inhaltsstoffe aus den Blattern des Ginkgo-Baumes (Ginkgo biloba L.). Arzneimittelforschung 18,537-539 (1967) (in German)

11 Kracher, L., Zagermann, P. and Krieglstein, J.: Effect of an extract of Ginkgo biloba on rat brain encrgy metabolism in hypoxia. Naunyn Schmicdebergs Arch. Pharmacol. 327, $31-$ 35 (1984)

12 Pincemail, J., Thirion, A., Dupuis, M., Braquet, P., Drieu, K. and Deby, C.: Ginkgo biloba extract inhibits oxygen species production generated by phorbol myristate acetate stimulated human leukocytes. Experientia 43, $181-184$ (1987)

13 Oyama, Y., Chikahisa, L., Hayashi, A., Ueha, T., Sato, M. and Matoba, H.: Triphenyltin-induced increase in the intracellular $\mathrm{Ca}^{2+}$ of dissociated mammalian CNS neuron: Its independent from voltage-dependent $\mathrm{Ca}^{2+}$ channels. Japan. J. Pharmacol. 58, 467-471 (1992)

14 St. John, P.A., Kell, W.M., Mazzetta, J.S., Lange, G.D. and Barker, J.L.: Analysis and isolation of embryonic mammalian neurons by fluorescence-activated cell sorting. J. Ncurosci. $\mathbf{6}$, $1492-1512$ (1986)

15 Kubo, K., Yoshitake, I., Kumada, Y., Shuto, K. and Nakamizo, N.: Radical scavenging action of flunarizine in rat brain in vitro. Arch. Int. Phamacodyn. Ther. 272, 283-295 (1984) 